Int. J. Electrochem. Sci., 15 (2020) 4148 - 4160

\title{
Enhancement Effect of Sodium-dodecyl Sulfate on Voltammetric Behaviour and Determination of Phentolamine Mesylate using Carbon Paste Electrode
}

\author{
Sen Fan ${ }^{2}$, Lei Ji ${ }^{1}$, Guoliang Mao ${ }^{1}$, Xin Sui ${ }^{1}$, Huan Wang ${ }^{1}$, Yuanhai $\mathrm{Zhu}^{1,{ }^{*}, \text { Hua Song }}{ }^{1}$ \\ ${ }^{1}$ College of Chemistry and Chemical Engineering, Northeast Petroleum University, Daqing 163318, \\ P.R. China \\ ${ }^{2}$ College of Petroleum Engineering, Northeast Petroleum University, Daqing 163318, P.R. China \\ *E-mail: yuanhaizhu@163.com
}

doi: $10.20964 / 2020.05 .17$

Received: 1 January 2020 / Accepted: 20 February 2020 / Published: 10 April 2020

\begin{abstract}
A carbon paste electrode (CPE) in the presence of Sodium-dodecyl Sulfate (SDS) was used for determination of phentolamine mesylate (PM), an important cardiovascular dilatation drug. Experiment shows that the drug exhibiting low redox activity at naked CPE can produce a sensitive anodic peak current in the presence of SDS. Investigation indicates that the oxidation of PM at CPE in the presence of SDS is one electron/one proton process which is controlled by adsorption. Under optimal conditions, the anodic peak current is linear to the concentrations of PM within the range of $3.0 \times 10^{-8}-1.0 \times 10^{-6} \mathrm{M}$ with a detection limit of about $1.0 \times 10^{-8} \mathrm{M}$. The electrode shows good stability and reproducibility. The electrochemical method proposed has been successfully applied to the determination of phentolamine mesylate in pharmaceutical formulations.
\end{abstract}

Keywords: phentolamine mesylate; SDS; carbon paste electrode; electrochemical method

\section{$\underline{\text { FULL TEXT }}$}

(C) 2020 The Authors. Published by ESG (www.electrochemsci.org). This article is an open access article distributed under the terms and conditions of the Creative Commons Attribution license (http://creativecommons.org/licenses/by/4.0/). 